\title{
LIDAR-DERIVED ELEVATION DATA FOR TURNAGAIN PASS, SOUTHCENTRAL ALASKA, SEPTEMBER 2, 2018
}

Katreen Wikstrom Jones, Gabriel J. Wolken, Ronald P. Daanen, and Andrew M. Herbst

Raw Data File 2020-16

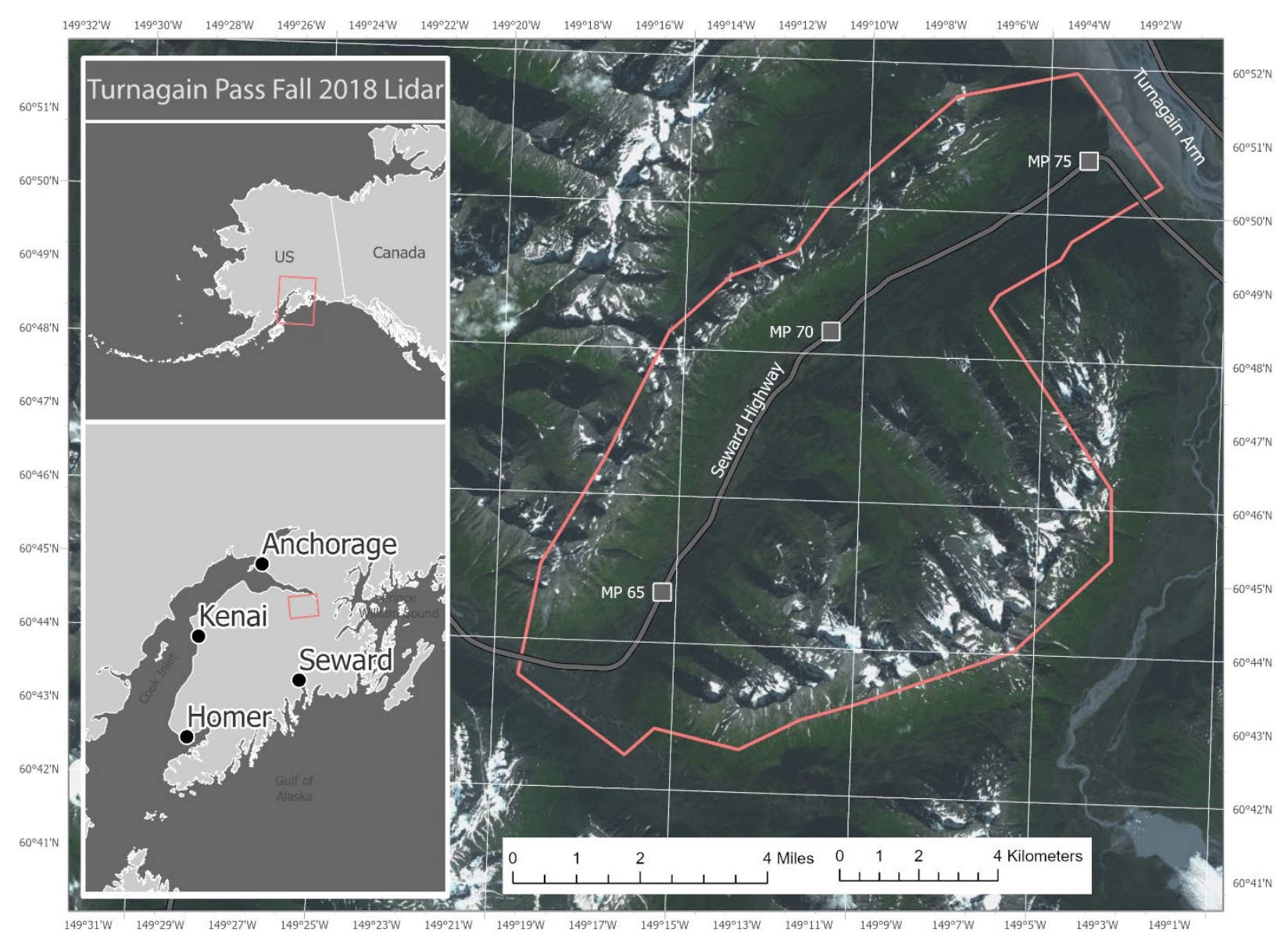

Location map of survey area with ortho-image base layer.

This report has not been reviewed for technical content or for conformity to the editorial standards of DGGS.

2021

STATE OF ALASKA

DEPARTMENT OF NATURAL RESOURCES

DIVISION OF GEOLOGICAL \& GEOPHYSICAL SURVEYS

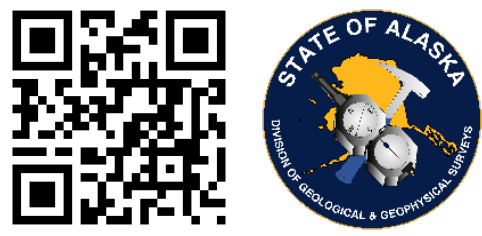


STATE OF ALASKA

Mike Dunleavy, Governor

DEPARTMENT OF NATURAL RESOURCES

Corri A. Feige, Commissioner

\section{DIVISION OF GEOLOGICAL \& GEOPHYSICAL SURVEYS}

Steve Masterman, State Geologist \& Director

Publications produced by the Division of Geological \& Geophysical Surveys are available to download from the DGGS website (dggs.alaska.gov). Publications on hard-copy or digital media can be examined or purchased in the Fairbanks office:

\section{Alaska Division of Geological \& Geophysical Surveys (DGGS)}

3354 College Road | Fairbanks, Alaska 99709-3707

Phone: 907.451 .5010 | Fax 907.451.5050

dggspubs@alaska.gov | dggs.alaska.gov

DGGS publications are also available at:

Alaska State Library, Historical

Collections \& Talking Book Center

395 Whittier Street

Juneau, Alaska 99801

Alaska Resource Library and

Information Services (ARLIS)

3150 C Street, Suite 100

Anchorage, Alaska 99503

\section{Suggested citation:}

Wikstrom Jones, Katreen, Wolken, G.J., Daanen, R.P., and Herbst, A.M., 2021, Lidar-derived elevation data for Turnagain Pass, southcentral Alaska, September 2, 2018: Alaska Division of Geological \& Geophysical

Surveys Raw Data File 2020-16, 6 p. https://doi.org/10.14509/30567
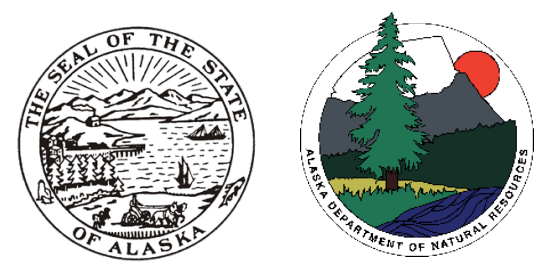


\title{
LIDAR-DERIVED ELEVATION DATA FOR TURNAGAIN PASS, SOUTHCENTRAL ALASKA, SEPTEMBER 2, 2018 \\ Katreen Wikstrom-Jones ${ }^{1}$, Gabriel J. Wolken ${ }^{1}$, Ronald P. Daanen ${ }^{1}$, and Andrew M. Herbst ${ }^{1}$
}

\begin{abstract}
The State of Alaska Division of Geological \& Geophysical Surveys (DGGS) used lidar to produce a digital terrain model (DTM) and digital surface model (DSM) of Turnagain Pass, southcentral Alaska, during snow-free ground conditions. The lidar and Global Navigation Satellite System (GNSS) data were collected on September 2, 2018, and processed using Terrasolid. This data collection is being released as a Raw Data File with an open end-user license. All files can be downloaded from the DGGS website at https://doi.org/10.14509/30567.
\end{abstract}

\section{INTRODUCTION}

The goal of the survey is to provide snow-free surface elevations for deriving snow depth distribution models with repeat surveys during snow-covered surface conditions. This data release is one of a series of DGGS publications to present elevation data.

\section{LIST OF DELIVERABLES}

Classified Points

DSM and DTM

Intensity Image

Metadata

\section{MISSION PLAN}

\section{Airborne Survey Details}

This dataset includes point cloud data, a 32-bit digital terrain model and digital surface model, and an intensity image covering Turnagain Pass located southeast of Anchorage within the Chugach National Forest on the Kenai Peninsula in southcentral Alaska. This lidar survey was flown at an average elevation of $200 \mathrm{~m}$ above ground level and a ground speed of approximately 40 meters per second with a fixed-wing Cessna 180. Elevation data were acquired with a Riegl VUX1-LR laser scanner integrated with a GNSS and Northrop Grumman IMU system. The integration was designed by Phoenix LiDAR systems. Lidar data were acquired at a pulse rate ranging from 50,000 pulses per second in the alpine areas to 400,000 pulses per second over forested areas, a scan rate of 200 revolutions per second, and a scan angle range of 80-280 degrees.

\footnotetext{
${ }^{1}$ Alaska Division of Geological \& Geophysical Surveys, 3354 College Road, Fairbanks, Alaska 99709
} 
The total area surveyed was approximately $60 \mathrm{mi}^{2}\left(160 \mathrm{~km}^{2}\right)$. This data release is complete and there is no over collect, except for the aircraft turns that were eliminated from the dataset. There are a few areas where data coverage is limited due to laser range exceedance, which is related to the slow response of the fixed wing aircraft to the fast elevation change along the flight path (e.g., in canyons) (fig. 1).

\section{Weather Conditions and Flight Times}

The lidar data were collected on September 2, 2018. The sky was clear. No abnormalities were observed during the flights.

\section{Lidar Point Cloud Details}

The ground-classified point cloud from which the DTM was derived has an average point spacing of $43 \mathrm{~cm}$ ( $43 \mathrm{~cm}$ on the ground in open alpine areas and $32 \mathrm{~cm}$ below dense vegetation in the valley) and an average point density of 2.3 points per square meter (fig. 2 ). The point cloud that was used to generate the DSM (which includes points classified as grounds, and low, medium, and high vegetation), has a point spacing of $20 \mathrm{~cm}$ and a point density of 5 points per square meter.

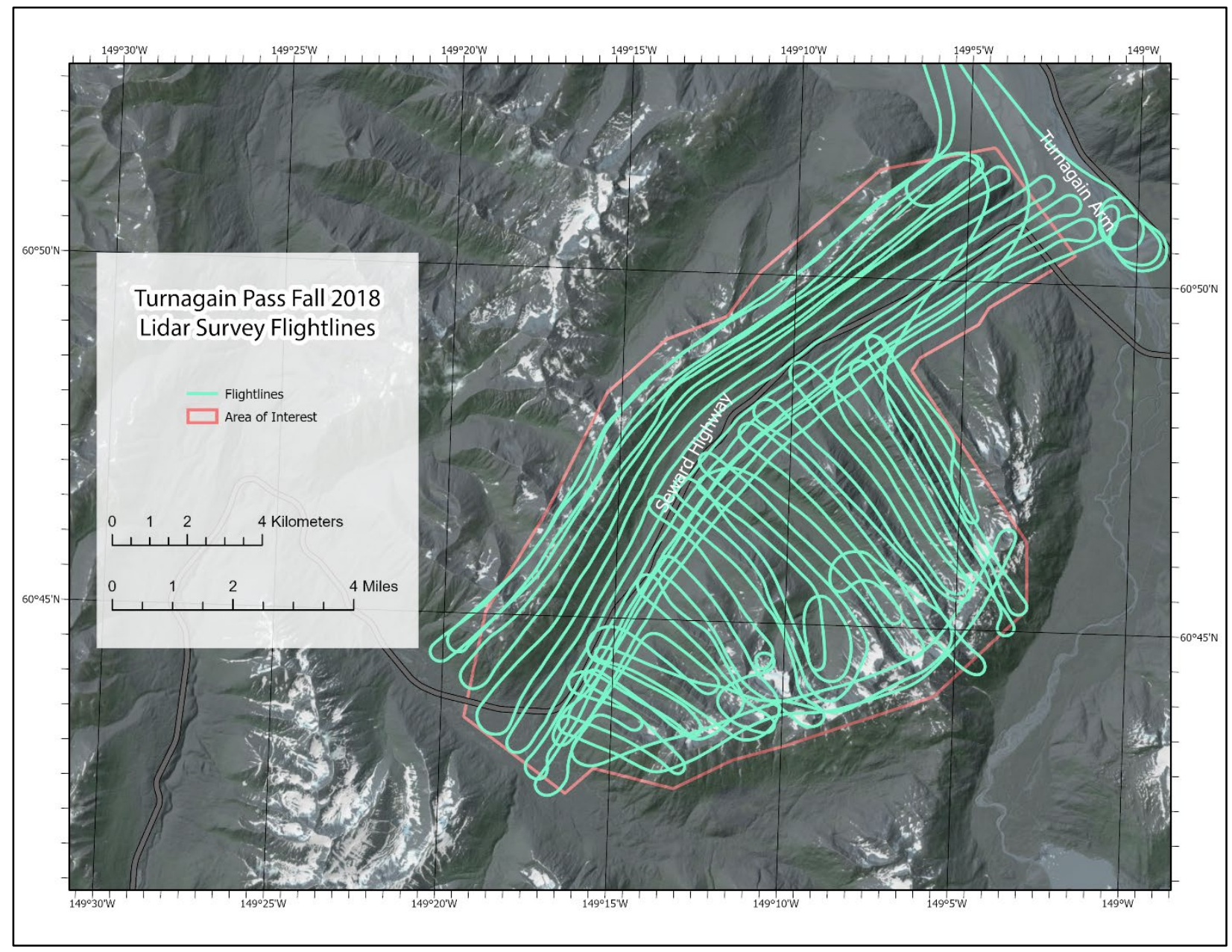

Figure 1. Project flightlines. 


\section{PROCESSING REPORT}

\section{Lidar Dataset Processing}

Raw data were processed using Terrasolid software to produce integrated files for navigation correction and a point cloud for calibration. The navigation was corrected using Inertial Explorer software, where the GNSS and IMU data are integrated to establish correct flight path and orientation of the lidar sensor.

Internal consistency of the dataset was improved by calibrating the point cloud data using global, flight line, and fluctuation (within individual flightlines) tielines in Terrasolid software. The point cloud was classified for ground points as well as low, medium, and high vegetation (0.01-0.5 $\mathrm{m}, 0.5-3 \mathrm{~m}$, and 3-60 $\mathrm{m}$ heights above the ground, respectively, in accordance with ASPRS lidar classification codes). Some manual processing was required to eliminate erratically placed points and misclassified ground points. All low points and air points were eliminated from the dataset.

A LAS dataset was created in ArcMAP, from which a $50 \mathrm{~cm}$ DTM, DSM, and intensity image were produced. The DTM was derived from elevation values of ground-classified points only, and built using the binning technique of minimum elevation and linear void fill. The DSM was derived from elevation values from first returns from all point classes, and built using the binning technique of average elevation values and linear void fill. The intensity image was derived from intensity values of first return points.

\section{Digital Terrain Model}

The DTM represents elevations of ground surfaces, excluding vegetation, bridges, buildings, etc. The DTM is a single-band, 32-bit float GeoTIFF file, with a ground sample distance of $50 \mathrm{~cm}$. No Data value is set to $-3.40282306074 \mathrm{e}+038$.

\section{Digital Surface Model}

The DSM represents surface elevations, for example heights of vegetation, buildings, bridges, etc. The DSM is a single band, 32-bit GeoTIFF file, with a ground sample distance of 50 $\mathrm{cm}$. No Data value is set to $-3.40282306074 \mathrm{e}+038$.

\section{Intensity Image}

The intensity image represents the return strengths of the first return laser pulses. The intensity image is a single band, 32-bit GeoTIFF file, with a ground sample distance of 50 centimeter and normalized to the $0-255$ range. No Data value is set to $-3.40282306074 \mathrm{e}+038$.

\section{SURVEY REPORT}

\section{Ground Survey Details}

Ground control and check points were collected on September 2, 2018. A Trimble R7 GNSS receiver with Zephyr-2 antenna was deployed near the center of the study area and provided a base station occupation and real-time kinematic (RTK) corrections to points surveyed with a rover Trimble R8-4 GNSS receiver (internal antenna). 78 total ground control points and check points 
were collected to be used for calibration and assessment of the vertical accuracy of the point cloud. All points were collected on a paved road surface.

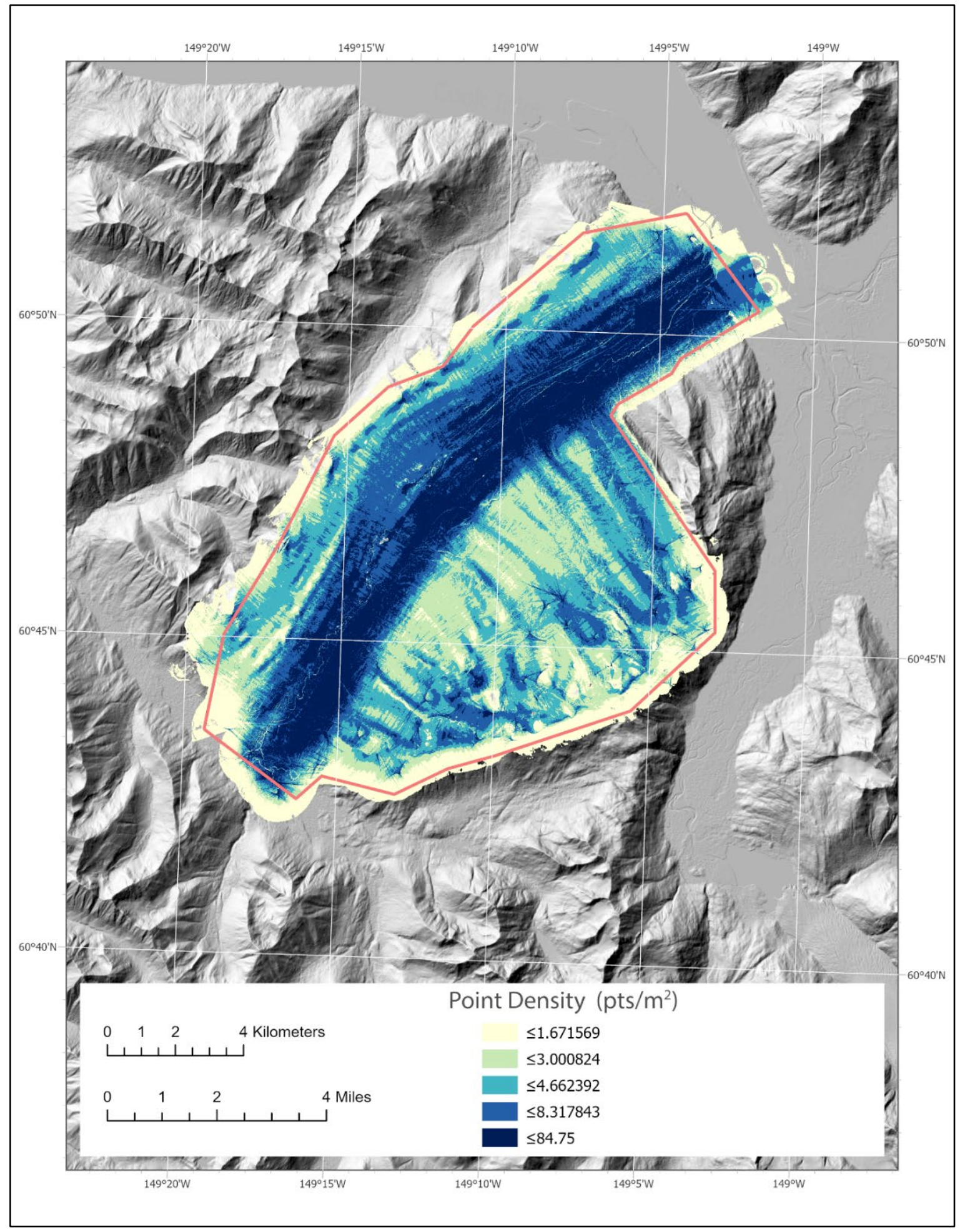

Figure 2. Ground point density displayed as 1-meter raster for the survey. 


\section{Coordinate system and Datum}

All data were processed and delivered in NAD83 (2011) UTM6N and vertical datum NAVD88 with a geoid correction following the latest GEOID12B for Alaska.

\section{Vertical Accuracy}

The elevation values of 62 ground control points were compared with the elevation values of the lidar points classified as ground points. The average vertical offset was corrected with a $\mathrm{z}$ transformation. 15 check points were used to determine the final accuracy of the z-transformed lidar point cloud. The lidar point cloud had a vertical offset of $+2.2 \mathrm{~cm}$ (root mean squared error [RMSE] $3.6 \mathrm{~cm}$ ) compared to ground control, therefore a vertical transformation of $-2.2 \mathrm{~cm}$ was applied to the lidar point cloud (appendix 1). The final accuracy assessment showed a mean vertical offset of $-0.3 \mathrm{~cm}$ and RMSE of $3.3 \mathrm{~cm}$ (appendix 2). Relative accuracy for this dataset was evaluated as the interswath overlap consistency and was measured at $1.2 \mathrm{~cm}$ RMSE.

\section{ACKNOWLEDGMENTS}

These data products were funded by U.S. Geological Surveys and Alaska Department of Natural Resources, Division of Geological \& Geophysical Surveys. We thank Clearwater Air for their aviation expertise and contribution to these data products. 


\section{APPENDIX 1: GROUND CONTROL POINTS}

\begin{tabular}{|c|c|c|c|c|c|}
\hline Number & Easting (m) & Northing $(\mathrm{m})$ & Known Z (m) & Laser Z (m) & $\mathrm{Dz}(\mathrm{m})$ \\
\hline 1 & 379278.224 & 6740620.077 & 291.995 & 292.03 & 0.04 \\
\hline 2 & 379250.008 & 6740563.274 & 290.647 & 290.66 & 0.01 \\
\hline 3 & 379220.714 & 6740502.224 & 289.221 & 289.24 & 0.02 \\
\hline 4 & 379160.19 & 6740384.617 & 286.252 & 286.28 & 0.03 \\
\hline 5 & 379102.752 & 6740265 & 284.396 & 284.41 & 0.01 \\
\hline 6 & 379046.551 & 6740155.735 & 283.986 & 284.01 & 0.02 \\
\hline 7 & 379006.714 & 6740073.262 & 284.295 & 284.30 & 0.01 \\
\hline 8 & 378915.716 & 6739889.098 & 285.193 & 285.23 & 0.04 \\
\hline 9 & 378914.119 & 6739904.678 & 285.109 & 285.14 & 0.03 \\
\hline 10 & 378951.303 & 6739985.044 & 284.75 & 284.74 & -0.01 \\
\hline 11 & 378983.971 & 6740055.846 & 284.427 & 284.43 & 0.00 \\
\hline 12 & 379062.544 & 6740225.849 & 284.048 & 284.04 & -0.01 \\
\hline 13 & 379076.448 & 6740256.109 & 284.244 & 284.22 & -0.02 \\
\hline 14 & 379106.389 & 6740319.061 & 284.927 & 284.90 & -0.03 \\
\hline 15 & 379131.278 & 6740371.021 & 285.795 & 285.81 & 0.02 \\
\hline 16 & 379185.769 & 6740484.51 & 288.549 & 288.58 & 0.03 \\
\hline 17 & 379212.339 & 6740539.647 & 290.257 & 290.25 & -0.01 \\
\hline 18 & 379244.158 & 6740605.541 & 292.234 & 292.22 & -0.01 \\
\hline 19 & 379271.682 & 6740658.826 & 293.598 & 293.61 & 0.01 \\
\hline 20 & 379306.985 & 6740721.494 & 295.273 & 295.27 & 0.00 \\
\hline 21 & 379328.52 & 6740756.893 & 296.172 & 296.19 & 0.02 \\
\hline 22 & 379349.382 & 6740790.711 & 296.884 & 296.92 & 0.04 \\
\hline 23 & 379377.048 & 6740835.399 & 297.82 & 297.85 & 0.03 \\
\hline 24 & 379434.273 & 6740927.745 & 300.321 & 300.37 & 0.05 \\
\hline 25 & 379454.098 & 6740959.727 & 301.106 & 301.12 & 0.01 \\
\hline 26 & 379465.702 & 6740954.012 & 301.273 & 301.30 & 0.03 \\
\hline 27 & 379459.433 & 6740930.024 & 300.626 & 300.65 & 0.02 \\
\hline 28 & 379423.929 & 6740872.874 & 299.1 & 299.13 & 0.03 \\
\hline 29 & 379399.918 & 6740834.243 & 298.069 & 298.09 & 0.02 \\
\hline 30 & 379385.756 & 6740811.446 & 297.377 & 297.41 & 0.03 \\
\hline 31 & 379347.656 & 6740750.2 & 295.666 & 295.69 & 0.02 \\
\hline 32 & 379301.411 & 6740669.963 & 293.433 & 293.41 & -0.02 \\
\hline 33 & 377190.656 & 6736921.804 & 243.428 & 243.44 & 0.01 \\
\hline 34 & 377188.078 & 6736904.201 & 243.179 & 243.24 & 0.06 \\
\hline 35 & 377179.891 & 6736859.998 & 242.387 & 242.40 & 0.01 \\
\hline 36 & 377154.62 & 6736808.988 & 241.308 & 241.36 & 0.05 \\
\hline 37 & 377134.148 & 6736766.343 & 240.402 & 240.45 & 0.05 \\
\hline 38 & 377113.185 & 6736722.282 & 239.426 & 239.48 & 0.05 \\
\hline 39 & 377102.06 & 6736698.809 & 238.945 & 239.01 & 0.07 \\
\hline 40 & 377070.54 & 6736660.05 & 238.014 & 238.06 & 0.05 \\
\hline
\end{tabular}




\begin{tabular}{|c|c|c|c|c|c|}
\hline Number & Easting (m) & Northing (m) & Known Z (m) & Laser $\mathrm{Z}(\mathrm{m})$ & $\mathrm{Dz}(\mathrm{m})$ \\
\hline 41 & 377096.884 & 6736709.022 & 239.075 & 239.15 & 0.08 \\
\hline 42 & 377120.642 & 6736756.862 & 240.115 & 240.15 & 0.04 \\
\hline 43 & 377143.424 & 6736802.815 & 241.097 & 241.13 & 0.03 \\
\hline 44 & 377180.458 & 6736877.464 & 242.688 & 242.72 & 0.03 \\
\hline 45 & 380326.304 & 6742081.355 & 318.691 & 318.60 & -0.09 \\
\hline 46 & 380337.023 & 6742110.258 & 318.668 & 318.62 & -0.05 \\
\hline 47 & 380354.521 & 6742155.551 & 318.397 & 318.45 & 0.05 \\
\hline 48 & 380382.777 & 6742228.147 & 317.628 & 317.68 & 0.05 \\
\hline 49 & 380445.075 & 6742368.69 & 314.73 & 314.76 & 0.03 \\
\hline 50 & 380462.321 & 6742397.666 & 313.76 & 313.77 & 0.01 \\
\hline 51 & 380531.5 & 6742490.28 & 309.915 & 309.96 & 0.05 \\
\hline 52 & 380559.075 & 6742519.781 & 308.551 & 308.57 & 0.02 \\
\hline 53 & 380633.272 & 6742570.691 & 306.165 & 306.22 & 0.06 \\
\hline 54 & 380667.649 & 6742595.905 & 305.55 & 305.56 & 0.01 \\
\hline 55 & 380688.072 & 6742610.637 & 305.288 & 305.31 & 0.02 \\
\hline 56 & 380726.808 & 6742638.603 & 304.959 & 304.97 & 0.01 \\
\hline 57 & 380747.201 & 6742653.328 & 304.769 & 304.79 & 0.02 \\
\hline 58 & 380766.291 & 6742667.105 & 304.655 & 304.67 & 0.02 \\
\hline 59 & 380785.993 & 6742681.365 & 304.501 & 304.50 & 0.00 \\
\hline 60 & 380647.935 & 6742581.681 & 305.887 & 305.93 & 0.04 \\
\hline 61 & 380591.485 & 6742535.625 & 307.334 & 307.36 & 0.03 \\
\hline 62 & 380464.996 & 6742381.077 & 313.848 & 313.93 & 0.08 \\
\hline Average $\mathrm{dz}(\mathrm{m})$ & 0.022 & & & & \\
\hline Minimum dz (m) & -0.091 & & & & \\
\hline Maximum dz (m) & 0.082 & & & & \\
\hline $\begin{array}{c}\text { Average } \\
\text { magnitude (m) }\end{array}$ & 0.030 & & & & \\
\hline $\begin{array}{l}\text { Root mean } \\
\text { square error }(\mathrm{m})\end{array}$ & 0.036 & & & & \\
\hline $\begin{array}{c}\text { Standard } \\
\text { deviation (m) }\end{array}$ & 0.029 & & & & \\
\hline
\end{tabular}


APPENDIX 2: CHECK POINTS

\begin{tabular}{|c|c|c|c|c|c|}
\hline Number & Easting $(\mathrm{m})$ & Northing (m) & Known Z (m) & Laser Z (m) & $\mathrm{Dz}(\mathrm{m})$ \\
\hline 1 & 379202.3 & 6740465 & 288.254 & 288.26 & 0.006 \\
\hline 2 & 378952.6 & 6739963 & 284.814 & 284.79 & -0.024 \\
\hline 3 & 379016 & 6740125 & 284.119 & 284.11 & -0.009 \\
\hline 4 & 379159.6 & 6740430 & 287.129 & 287.12 & -0.009 \\
\hline 5 & 379294.1 & 6740699 & 294.683 & 294.65 & -0.033 \\
\hline 6 & 379406.9 & 6740884 & 299.153 & 299.15 & -0.003 \\
\hline 7 & 379447.5 & 6740911 & 300.158 & 300.17 & 0.012 \\
\hline 8 & 379316.6 & 6740698 & 294.267 & 294.18 & -0.087 \\
\hline 9 & 377165.8 & 6736832 & 241.765 & 241.81 & 0.045 \\
\hline 10 & 377082.4 & 6736657 & 238.052 & 238.08 & 0.028 \\
\hline 11 & 377163.8 & 6736844 & 241.938 & 241.97 & 0.032 \\
\hline 12 & 380374.7 & 6742207 & 317.888 & 317.93 & 0.042 \\
\hline 13 & 380542.5 & 6742503 & 309.316 & 309.3 & -0.016 \\
\hline 14 & 380707 & 6742624 & 305.163 & 305.17 & 0.007 \\
\hline 15 & 380805.9 & 6742696 & 304.421 & 304.39 & -0.031 \\
\hline $\begin{array}{c}\text { Average } \\
\text { dz (m) }\end{array}$ & -0.003 & & & & \\
\hline $\begin{array}{l}\text { Minimum } \\
d z(m)\end{array}$ & -0.087 & & & & \\
\hline $\begin{array}{l}\text { Maximum } \\
\mathrm{dz}(\mathrm{m})\end{array}$ & 0.045 & & & & \\
\hline $\begin{array}{c}\text { Average } \\
\text { magnitude } \\
(\mathrm{m})\end{array}$ & 0.026 & & & & \\
\hline $\begin{array}{c}\text { Root } \\
\text { mean } \\
\text { square } \\
\text { error }(m)\end{array}$ & 0.033 & & & & \\
\hline $\begin{array}{c}\text { Standard } \\
\text { deviation } \\
\text { (m) }\end{array}$ & 0.034 & & & & \\
\hline
\end{tabular}

